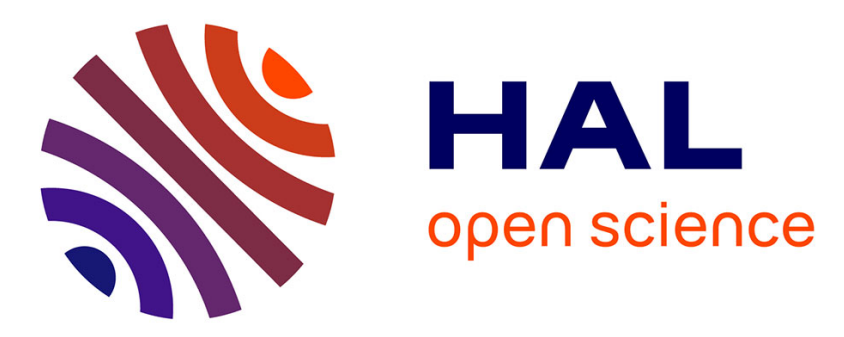

\title{
Watt-level visible laser in double-clad Pr 3+ -doped fluoride fiber pumped by a GaN diode
}

Esrom Kifle, Florent Starecki, Pavel Loiko, Solenn Cozic, Franck Joulain, Thibaud Berthelot, Thierry Georges, Dragan Stojcevski, Damien Deubel, Patrice Camy

\section{To cite this version:}

Esrom Kifle, Florent Starecki, Pavel Loiko, Solenn Cozic, Franck Joulain, et al.. Watt-level visible laser in double-clad Pr 3+-doped fluoride fiber pumped by a GaN diode. Optics Letters, 2021, 46 (1), pp.74. 10.1364/OL.413673 . hal-03215880

\section{HAL Id: hal-03215880 \\ https://hal.science/hal-03215880}

Submitted on 7 Oct 2021

HAL is a multi-disciplinary open access archive for the deposit and dissemination of scientific research documents, whether they are published or not. The documents may come from teaching and research institutions in France or abroad, or from public or private research centers.
L'archive ouverte pluridisciplinaire HAL, est destinée au dépôt et à la diffusion de documents scientifiques de niveau recherche, publiés ou non, émanant des établissements d'enseignement et de recherche français ou étrangers, des laboratoires publics ou privés. 


\title{
Watt-level visible laser in double-clad $\mathrm{Pr}^{3+}$-doped fluoride fiber pumped by a GaN diode
}

\author{
Esrom Kifle, ${ }^{1}$ Florent Starecki, ${ }^{1}$ Pavel Loiko ${ }^{1}$, Solenn Cozic, ${ }^{2}$ Franck \\ Joulain, ${ }^{2}$ Thibaud Berthelot, ${ }^{2}$ Thierry Georges, ${ }^{3}$ Dragan StojCeVski, ${ }^{4}$ \\ Damien Deubel, ${ }^{4}$ And Patrice Camy ${ }^{1, *}$
}

\author{
${ }^{1}$ Centre de recherche sur les lons, les Matériaux et la Photonique (CIMAP), UMR 6252 CEA-CNRS-ENSICAEN, Université de Caen \\ Normandie, 6 Boulevard du Maréchal Juin, 14050 Caen Cedex 4, France \\ ${ }^{2}$ Le Verre Fluoré, rue Gabriel Voisin, Campus de Ker-Lann, 35170 Bruz, France \\ ${ }^{3}$ Oxxius SA, 4 rue Louis de Broglie 22300 Lannion \\ ${ }^{4}$ Kerdry, 5 rue Louis de Broglie, 22300 Lannion, France \\ *Corresponding author: patrice.camy@ensicaen.fr
}

Received XX Month XXXX; revised XX Month, XXXX; accepted XX Month XXXX; posted XX Month XXXX (Doc. ID XXXXX); published XX Month XXXX

\begin{abstract}
We report on a red Praseodymium fiber laser delivering $1.07 \mathrm{~W}$ at $634.5 \mathrm{~nm}$ with a slope efficiency of $20.7 \%$ ( $v s$. the incident pump), a laser threshold of $0.55 \mathrm{~W}$ and a single-mode output $\left(\mathrm{M}^{2}{ }_{\mathrm{x}, \mathrm{y}}<1.1\right)$ in the quasi-continuouswave regime. It is based on a $0.6 \mathrm{~mol} \% \mathrm{Pr}^{3+}$-doped ZBLAN double-clad fiber with a $5.5 \mu \mathrm{m}$ core, a double D-shaped (diameters: 115/125 $\mu \mathrm{m}$ ) inner cladding and a length of $5.0 \mathrm{~m}$. The fiber is pumped by a multimode $443-\mathrm{nm}$ GaN diode. The laser design is optimized using a numerical model. The proposed concept is suitable for the development of diode-pumped high brightness watt-level visible Praseodymium fiber lasers. (C) 2020 Optical Society of America
\end{abstract}

http://dx.doi.org/10.1364/OL.99.099999

Trivalent praseodymium $\left(\mathrm{Pr}^{3+}\right)$ is the most widespread rare-earth ion for direct generation of visible laser light [1]. It exhibits high absorption cross-sections in the blue, relatively long lifetime of the upper laser level and abundant emission lines falling into the blue, green, orange and red spectral ranges. $\mathrm{Pr}^{3+}$ ions also enable wavelength tunable laser operation [2,3]. Visible Pr lasers are of practical use for solid-state lighting, data storage, fiber optics communications, biomedical applications and quantum optics.

Among the host matrices for $\mathrm{Pr}^{3+}$ doping, fluoride materials were found to be particularly suitable as they provide low phonon energies leading to long luminescence lifetimes of the emitting state (thermally coupled ${ }^{3} \mathrm{P}_{\mathrm{J}} /{ }^{1} \mathrm{I}_{6}$ levels) and weak crystal fields leading to relatively high position of energy levels of the $4 f^{n-1} 5 d^{1}$ configuration responsible for strong excited-state absorption in $\mathrm{Pr}^{3+}$-doped materials [1]. So far, various fluoride single-crystals (e.g., $\mathrm{LiYF}_{4}, \mathrm{KY}_{3} \mathrm{~F}_{10}, \mathrm{BaY}_{2} \mathrm{~F}_{8}$, etc.) doped with $\mathrm{Pr}^{3+}$ ions were employed in visible bulk lasers [4-7]. Metz et al. designed a
Pr:LiYF 4 laser delivering $2.9 \mathrm{~W}$ at $523 \mathrm{~nm}$ with a record-high slope efficiency of $72 \%$ using an optically pumped semiconductor laser

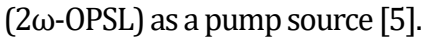

$\mathrm{Pr}^{3+}$-doped fluoride glasses (e.g., those in the $\mathrm{ZrF}_{4}$ system) in the form of fibers were also employed in visible fiber lasers [8-11]. The development of fiber sources is particularly attractive because of their inherent advantages such as excellent beam quality, stability, small footprint and flexible configuration. Note that one of the key factors for the design of Pr lasers is the cross-relaxation (CR) among the adjacent active ions depopulating the upper laser manifold and shortening its lifetime [12]. The CR is enhanced with the doping level which limits the $\mathrm{Pr}^{3+}$ concentration in gain media. This is however not critical for fiber lasers where high absorption efficiencies can be reached.

Fujimoto et al. used a $0.3 \mathrm{~mol} \% \mathrm{Pr}^{3+}$-doped fluoro-aluminate single-clad multimode fiber ( $4 \mathrm{~cm}$-long) pumped by two GaN laser diodes to demonstrate watt-level laser emission in the green and red [10]. In the latter case, a quasi-continuous-wave (quasi-CW) laser generated a peak power of $1.24 \mathrm{~W}$ at $638 \mathrm{~nm}$ with a slope efficiency of $46.6 \%$ (vs. the absorbed pump power). Kajikawa et al. proposed to use the double-clad fiber design to allow for further power scaling [13]. Using the same fluoro-aluminate glass, the authors achieved $0.25 \mathrm{~W}$ at $639 \mathrm{~nm}$ with a slope efficiency of $43.4 \%$ corresponding to a single-mode output. Further power scaling reaching $2.0 \mathrm{~W}$ at $638 \mathrm{~nm}$ was demonstrated in [14]. Note that in $[13,14]$, the potential of the double-clad design was not fully exploited because of the small inner cladding diameter (14 and 24 $\mu \mathrm{m}$ in $[13,14]$, respectively) and most likely predominantly core pumping (evidenced by the short fiber length of $10 \mathrm{~cm}$ ). Broadband wavelength tuning of Pr fluoride fiber lasers based on ZBLAN glasses was realized in [2].

Double-clad active fibers containing a single-mode core where the laser emission propagates and a multimode inner cladding for 
the pump are well suited for power scaling. The inner cladding being much larger than the core and having large numerical aperture (N.A.) enables easy coupling of pump light from laser diodes. Among the pump sources for Pr lasers, particularly GaN diodes offer the optimum solution in terms of compactness, costeffectiveness and power scalability $[6,10,15]$ (as compared to $2 \omega$ OPSLs). In the present work, we aimed to demonstrate a watt-level red Pr fiber laser fully exploiting the double-clad geometry making it very suitable for low-brightness GaN diode pumping.

First, we briefly characterize the key spectroscopic properties of the $\mathrm{Pr}^{3+}$-doped ZBLAN glass (measured in the present work). The absorption cross-section, $\sigma_{\mathrm{abs}}$, spectrum in the blue spectral range is shown in Fig. 1(a). For the ${ }^{3} \mathrm{H}_{4} \rightarrow{ }^{3} \mathrm{P}_{2}$ transition, the maximum $\sigma_{\text {abs }}$ is $1.08 \times 10^{-20} \mathrm{~cm}^{2}$ at $442 \mathrm{~nm}$ and the absorption bandwidth (FWHM) is $10 \mathrm{~nm}$. The emission spectrum of $\mathrm{Pr}^{3+}$ ions is shown in Fig. 1(b). The stimulated-emission (SE) cross-section, $\sigma_{\mathrm{SE}}$, for the ${ }^{3} \mathrm{P}_{0} \rightarrow{ }^{3} \mathrm{~F}_{2}$ transition, Fig. 1(c), falling into the red spectral range was calculated using the Füchtbauer-Ladenburg (F-L) equation to be $3.82 \times 10^{-20} \mathrm{~cm}^{2}$ at $635 \mathrm{~nm}$. Here, we considered a radiative lifetime $\tau_{\text {rad }}\left({ }^{3} \mathrm{P}_{0}\right)$ of $37 \mu$ s and a luminescence branching ratio $B(\mathrm{JJ})$ of $12.1 \%$ [16]. The typical luminescence decay curve for red emission (the decay from the ${ }^{3} \mathrm{P}_{0}$ state) is shown in Fig. 1(d) for the doping level of $0.6 \mathrm{~mol} \% \mathrm{Pr}$. It is well fitted using the Inokuti-Hirayama model considering a dipole-dipole transfer mechanism [17]. The mean luminescence lifetime $<\tau_{\text {um }}>$ shows a relatively weak dependence on the Pr doping level, Fig. 1(e), and it equals $39.7 \mu$ s for $0.6 \mathrm{~mol} \%$ Pr doping.
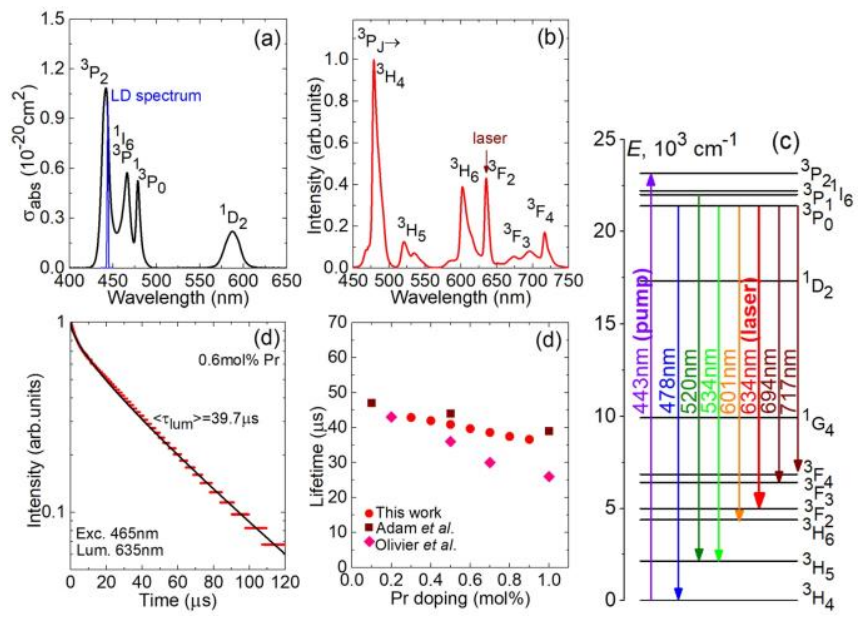

Fig. 1. Spectroscopy of $\mathrm{Pr}^{3+}$ ions in ZBLAN glass: (a) absorption crosssection, $\sigma_{\mathrm{abs}}$, spectrum in the blue spectral range, blue curve - the spectrum of the GaN diode; (b) luminescence spectrum, $\lambda_{\mathrm{exc}}=443 \mathrm{~nm}$, the arrow indicates the laser line; (c) the scheme of energy levels of $\mathrm{Pr}^{3+}$ ions in fluoride glass; (d) luminescence decay curve for $0.6 \mathrm{~mol} \%$ Pr doping, $\lambda_{\text {exc }}=465 \mathrm{~nm}, \lambda_{\text {lum }}=635 \mathrm{~nm}$, the curve represents the fit using the Inokuti-Hirayama model for $s=6$ [17]; (e) luminescence lifetime of the ${ }^{3} \mathrm{P}_{0}$ state $v s$. the Pr doping level, the literature data are shown for comparison $[16,18]$.

As a gain material, we used a $\mathrm{Pr}^{3+}$-doped ZBLAN fluoride fiber (Le Verre Fluoré) in the double-clad geometry. The doping level was $0.6 \mathrm{~mol} \% \mathrm{PrF}_{3}\left(N_{\mathrm{Pr}}=1.16 \times 10^{20} \mathrm{~cm}^{-3}\right)$. The core diameter was $5.5 \mu \mathrm{m}$ and the inner cladding made of a lower-index fluoride glass had a truncated circular (double D-shaped) profile with diameters of $115 / 125 \mu \mathrm{m}$ used to enhance the pump absorption. The outer cladding made of a resin polymer had a diameter of $180 \mu \mathrm{m}$. The fiber geometry is shown in Fig. 2(a). A confocal microscope image (in the reflection mode) of the polished fiber end-facet is shown in Fig. 2(b) (the core is not visualized due to the small refractive index contrast). The length of the fiber was $5.0 \mathrm{~m}$. The refractive indices of the core and inner cladding were 1.5096 and 1.5052 at the laser wavelength (635 nm), respectively. The numerical aperture (N.A.) of the fiber for the pump was 0.40 and for the laser emission, it was 0.12. Both fiber ends were mounted into SMA connectors. The end-facet of the fiber was polished and highly-reflective (HR) coated at $635 \mathrm{~nm}$ serving as a HR end mirror (M2). The coating was a dielectric multilayer structure deposited using a standard sputtering machine for laser mirror elaboration. The input facet was also polished for normal incidence and left uncoated. It was used as an input mirror (M1) both for pump coupling and as the output coupler having a reflectivity $R$ of $4.1 \%$ at the laser wavelength (determined only by the Fresnel loss). Both fiber ends were passively cooled. The fiber core supported up to 2 modes at the laser wavelength $\left(\mathrm{LP}_{01}\right.$ and $\mathrm{LP}_{11}$, confinement factors: $92.0 \%$ and $72.6 \%$, respectively, V-number: 3.12 ) and the inner cladding was highly multimode.
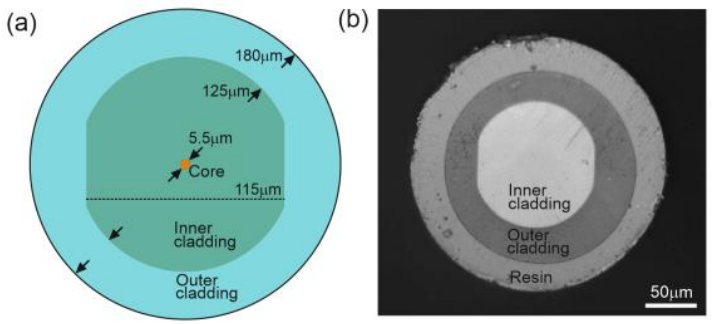

Fig. 2. (a) Scheme of the transverse profile of the double-clad fluoride fiber; (b) confocal laser microscope image of the polished end-facet of the fiber (the jacket is removed), reflection mode, $\lambda=405 \mathrm{~nm}$.

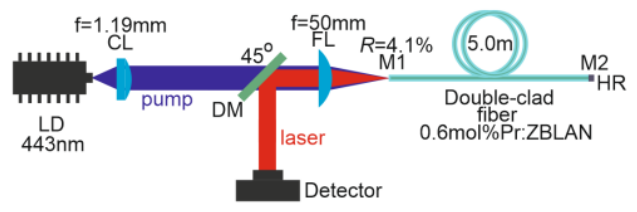

Fig. 3. Scheme of the red Pr fiber laser: LD - GaN laser diode, CL collimating cylindrical lens, FL - achromatic focusing lens, M1 and M2 cavity mirrors, HR - highly-reflective coating, DM - dichroic mirror.

The scheme of the laser is shown in Fig. 3. As a pump source, we used an open-space GaN laser diode (NUBM44, Nichia) emitting up to $\sim 6 \mathrm{~W}$ at $443 \mathrm{~nm}$ (emission bandwidth: $1.5 \mathrm{~nm}$, temperature drift of the emission wavelength: less than $2.5 \mathrm{~nm}$ ), Fig. 1(a). The pumping was in quasi-CW or true CW regimes. In the former case, it was electronically modulated with duty cycles 1:10, 1:5, 1:3 or $1: 2$ (the duration of the pump pulse was $\sim 0.5 \mathrm{~ms}$ ). The pump was collimated using an antireflection (AR) coated cylindrical short focal length ( $\mathrm{f}=1.19 \mathrm{~mm}$ ) lens (LIMO) and then focused into the fiber using an AR-coated achromatic lens ( $\mathrm{f}=50 \mathrm{~mm}$, Thorlabs). The mode diameter (at the $1 / \mathrm{e}^{2}$ level) at the fiber end-facet was $80 \pm 5 \mu \mathrm{m}$ (pumping into the inner cladding). The propagation loss 
for the pump radiation at $443 \mathrm{~nm} \alpha_{\text {loss,clad }}=1.54 \pm 0.2 \mathrm{~dB} / \mathrm{m}$ was determined from pump-transmission experiments using different fiber lengths. This high value of $\alpha$ oss,clad is related to parasitic absorption of blue light by the UV-curable resin polymer. The pump coupling efficiency was simply estimated from the Fresnel loss at the uncoated input facet of the fiber, $\eta_{\text {coupl }}=95.8 \%$. A dichroic mirror coated for high transmission (HT, $T>98 \%$ ) at 430 $480 \mathrm{~nm}$ and for HR $(R>99.7 \%)$ at $620-650 \mathrm{~nm}$ was inserted before the focusing lens at an angle of $45^{\circ}$. The laser spectrum was measured with an optical spectrum analyzer (Ando AQ-6315E).

The pump absorption in the fiber was determined from pumptransmission (cut-back) measurements for several lengths of the fiber $L$, Fig. 4(a). The pump was almost completely absorbed for $L$ $=5.0 \mathrm{~m}\left(\eta_{\mathrm{abs}}=93.4 \pm 1 \%\right)$. This value includes the propagation losses in the cladding at the pump wavelength. The points in Fig. 4(a) were fitted as $P_{\text {trans }} / P_{\text {coupl }}=\exp \left(-\left(\alpha_{\text {abs }} \times \Gamma_{\mathrm{p}}+\alpha_{\text {loss,dad }}\right) L\right)$, where $\alpha_{\text {abs }}=0.54 \times 10^{3} \mathrm{~dB} / \mathrm{m}$ is the absorption coefficient at the pump wavelength, cf. Fig. 1(a), and $\Gamma_{\mathrm{p}}=1.94 \times 10^{-3}$ is the power filling factor approximated as the ratio of the core / clad areas.

The spectral dependence of total losses for cladding-guided light (absorption by $\mathrm{Pr}^{3+}$ ions in the core and propagation losses in the inner cladding) was evaluated in a pump-transmission experiment using a halogen lamp, as shown by the grey curve in Fig. 4(b). To precise the absolute values, we performed similar measurements with lasers at 535 and $664 \mathrm{~nm}$ yielding $\alpha_{\text {loss,clad }}$ of $1.10 \pm 0.2 \mathrm{~dB} / \mathrm{m}$ and $0.62 \pm 0.1 \mathrm{~dB} / \mathrm{m}$, respectively. Thus, we were able to estimate

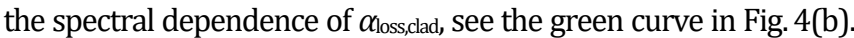
It rapidly increases for shorter wavelengths which is due to both light scattering in the fiber and absorption by the resin polymer as explained above. We also measured the total loss for light guided in the core using a He-Ne laser $(633 \mathrm{~nm})$ yielding the value of $0.43 \pm 0.1 \mathrm{~dB} / \mathrm{m}$. By subtracting the $\mathrm{Pr}^{3+}$ reabsorption at this wavelength (a phonon sideband of the ${ }^{3} \mathrm{H}_{4} \rightarrow{ }^{1} \mathrm{D}_{2}$ band), we obtain $\alpha_{\text {loss,core }}=0.19 \pm 0.1 \mathrm{~dB} / \mathrm{m}$ (due to light scattering).

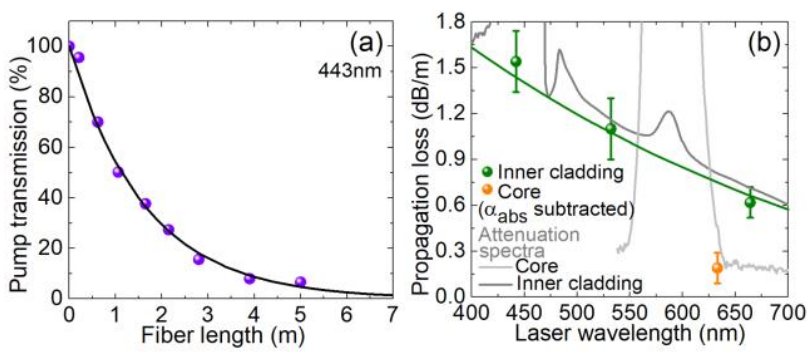

Fig. 4. Characterization of the double-clad $\mathrm{Pr}^{3+}$-doped fluoride fiber: transmission of the pump from the GaN diode vs. the fiber length: symbols - experimental data, curve - their fit; (b) propagation losses in the inner cladding and the core (symbols), the absorption losses due to $\mathrm{Pr}^{3+}$ ions are subtracted. The attenuation spectra (the grey curves) for light propagating in the core and cladding are shown for comparison.

The input-output dependences of the Pr fiber laser operating in the quasi-CW regime with various duty cycles ranging from 1:10 to 1:2 are shown in Fig. 5(a). These data correspond to the bending diameter of the fiber of $20 \mathrm{~cm}$ showing almost no bending loss $(<0.5 \%$ reduction in the output power). For the $1: 10$ duty cycle, the laser generated a maximum peak output power of $1.07 \mathrm{~W}$ at 634.5 $\mathrm{nm}$ with a slope efficiency of $21.6 \%$ (with respect to the coupled pump power $\left.P_{\text {coupl }}\right)$. The laser threshold was at $0.55 \mathrm{~W}$ and the optical-to-optical efficiency was $18.1 \%$ for the maximum available peak pump power of $5.9 \mathrm{~W}$. The output dependence was linear well above the laser threshold. The laser linewidth was $\sim 0.6 \mathrm{~nm}$, Fig. 5(b). The laser operated for $>1$ hour without any degradation of its output power. For smaller pump duty cycles, the maximum peak output power gradually decreased, and it was $0.85 \mathrm{~W}$ for the 1:2 duty cycle. A thermal roll-over was observed for $P_{\text {coupl }}>3.5 \mathrm{~W}$ and assigned to parasitic heating of the outer cladding due to its absorption at the pump wavelength. To avoid the risk of thermal damage of the fiber, for the true $\mathrm{CW}$ experiment, we limited $P_{\text {coupl }}$ to $3.7 \mathrm{~W}$, so that the output power amounted to $0.46 \mathrm{~W}$. For further power scaling in the CW regime, additional attention should be paid for thermal management of the input fiber end.
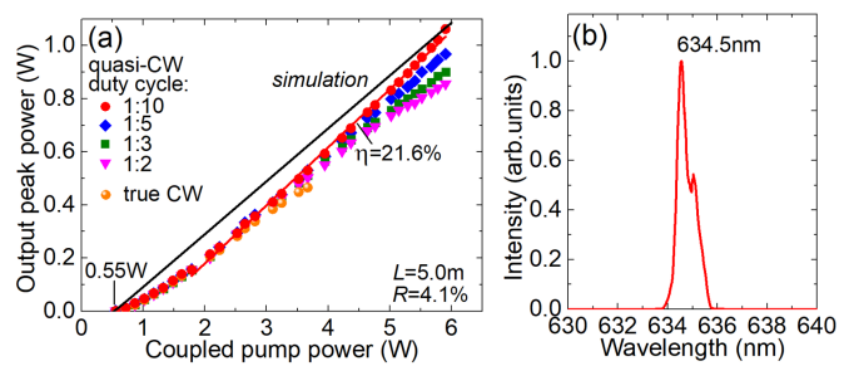

Fig. 5. Diode-pumped red Pr fiber laser: (a) input-output dependence, $\eta$-slope efficiency, black curve - simulation; (b) typical laser emission spectrum measured at $P_{\text {coupl }}=2.0 \mathrm{~W}$.

The typical far-field mode profile for the Pr fiber laser (bending diameter: $20 \mathrm{~cm}$ ) is shown in Fig. 6(a). The mode is nearly circular and the 1D intensity profiles are well fitted using the Gaussian distribution, Fig. 6(a). The measured beam quality factors $\mathrm{M}_{\mathrm{x}, \mathrm{y}}^{2}$ are 1.03 and 1.04, respectively, Fig. 6(b). We also studied more compact laser design employing a bending diameter of $8 \mathrm{~cm}$. This design did not lead to any noticeable alteration of the laser mode but a small power reduction was observed corresponding to the bending loss $\alpha_{\text {bend }}$ of $0.02 \pm 0.01 \mathrm{~dB} / \mathrm{m}$.
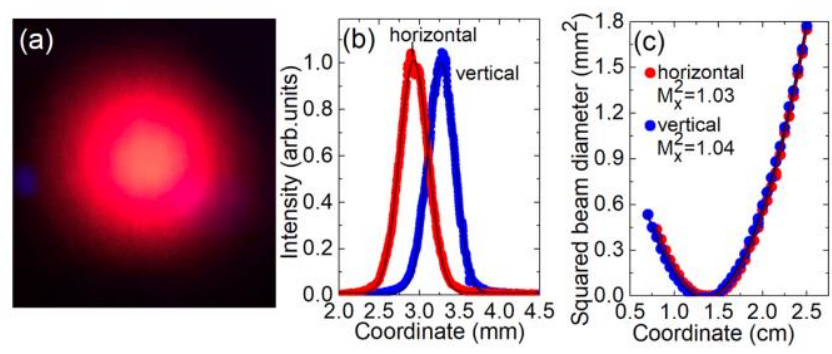

Fig. 6. (a) Typical far-field mode profile of the output beam from the Pr fiber laser; (b) 1D intensity profiles, symbols - experimental data, curves - their Gaussian fits; (c) evaluation of the $\mathrm{M}^{2} \mathrm{x}, \mathrm{y}$ parameters. The fiber bending diameter is $20 \mathrm{~cm}$.

The performance of the red Pr fiber laser was simulated using the model of a strongly pumped quasi-four-level laser developed by Kelson and Hardy [19]. The pump is coupled into the inner cladding and propagates along the negative direction (backward pumping). The fraction of pump coupled in the core is determined by the $\Gamma_{\mathrm{p}}$ factor. The laser light propagating both in positive and 
negative directions is mainly concentrated in the core; the $\mathrm{LP}_{01}$ mode is considered. The rate equation model includes the groundstate absorption, stimulated emission and spontaneous emission into the laser mode. We consider the propagation losses for both the laser and the pump. The steady-state rate equations and the propagation equation for the pump and laser are solved numerically using fourth-order Runge-Kutta algorithm [20,21]. The spectroscopic data reported in Fig. 1 were used.

The results of the simulations are shown in Fig. 7. For a fixed coupled pump power, the output power of the laser monotonously increases with reducing the reflectivity of the input mirror $R$, see Fig. 7(a). This justifies the use of an uncoated input fiber end in the present work. For a laser operating at $635 \mathrm{~nm}$, and for the given parameters, no significant improvement of the output power is expected when reducing $R$ below the value set by Fresnel losses (e.g., when applying an AR coating), Fig. 7(b). However, in this case, the laser threshold will notably increase. For the designed laser, there exist an optimum fiber length $(\sim 5 \mathrm{~m})$ which is determined by a counterplay between increasing pump absorption and raising cavity roundtrip losses in longer fibers, as shown in Fig. 7(c). For lower propagation losses, it is logically expected that the optimum $L$ value will increase, Fig. 7(d).

The model well explains the experimental output dependence for the Pr fiber laser, as shown by the blue curve in Fig. 5(a), and it predicts the potential of such double-clad fiber laser pumped by a single GaN laser diode.
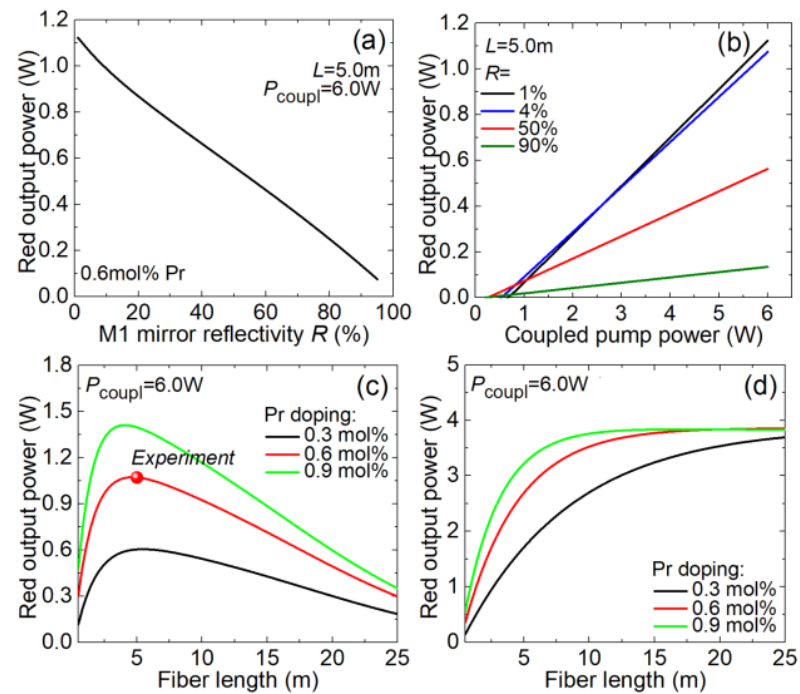

Fig. 7. Simulation of the performance of the diode-pumped red Pr fiber laser: (a) output power vs. the input mirror reflectivity $R, P_{\text {coupl }}=6.0 \mathrm{~W}$, $L=5.0 \mathrm{~m}$; (b) input-output dependences for different $R$ values, $L=5.0$ m; (c,d) output power vs. the fiber length $L$ for different Pr doping levels: (c) $\alpha_{\text {loss }}=1.54 \mathrm{~dB} / \mathrm{m}$ (inner cladding), $0.43 \mathrm{~dB} / \mathrm{m}$ (core), (d) lossless fiber, $\alpha_{\text {loss }} \equiv 0, P_{\text {coupl }}=6.0 \mathrm{~W}, R=4 \%$.

To conclude, we report on a concept of watt-level, high brightness visible lasers based on $\mathrm{Pr}^{3+}$-doped double-clad fluoride fibers with large inner cladding diameter and nearly single-mode core allowing for their efficient pumping with high-power and lowbrightness GaN blue laser diodes emitting at $443 \mathrm{~nm}$. The proof-ofthe-concept is verified using a $0.6 \mathrm{~mol} \% \mathrm{Pr}^{3+}$-doped ZBLAN fiber with the core / inner cladding diameters of $5.5 \mu \mathrm{m}$ and 115/125 $\mu \mathrm{m}$, respectively, which delivers $>1 \mathrm{~W}$ of red emission (in the quasi-CW regime) at $635 \mathrm{~nm}$ with high slope efficiency of $19.4 \%$ corresponding to a single-mode output. The performance of this laser is simulated revealing the necessity to consider an optimum fiber length / doping level. We believe that further power scaling and improvement of the laser efficiency are feasible via (i) reducing the propagation losses for the pump in the inner cladding, (ii) better thermal management of the fiber preventing its thermal damage, and (iii) coupling of several pump laser diodes into this high N.A. double-clad fiber gain medium.

Funding. European Union within the European Regional Development Fund (ERDF) (FEDER FSE-2014-2020). This Project was also supported in a joint framework between the French State, under the Future Investments Program, and the Bretagne and Normandy regions (FIZIC project).

Disclosures. The authors declare no conflicts of interest.

\section{References}

1. C. Kränkel, D. T. Marzahl, F. Moglia, G. Huber, and P. W. Metz, Laser Photon. Rev. 10, 548 (2016).

2. H. Okamoto, K. Kasuga, I. Hara, and Y. Kubota, Opt. Express 17, 20227 (2009).

3. P. W. Metz, S. Müller, F. Reichert, D.-T. Marzahl, F. Moglia, C. Kränkel, and G. Huber, Opt. Express 21, 31274 (2013).

4. P. Camy, J. L. Doualan, R. Moncorgé, J. Bengoechea, and U. Weichmann, Opt. Lett. 32, 1462 (2007).

5. P. W. Metz, F. Reichert, F. Moglia, S. Müller, D.-T. Marzahl, C. Kränkel, and G. Huber, Opt. Lett. 39, 3193 (2014).

6. F. Cornacchia, A. Di Lieto, M. Tonelli, A. Richter, E. Heumann, and G. Huber, Opt. Express 16, 15932 (2008).

7. D. Pabœuf, O. Mhibik, F. Bretenaker, P. Goldner, D. Parisi, and M. Tonelli, Opt. Lett. 36, 280 (2011).

8. R.G. Smart, J.N. Carter, A.C. Tropper, D.C. Hanna, S.T. Davey, S.F. Carter, and D. Szebesta, Opt. Commun. 86, 333 (1991).

9. J. Nakanishi, T. Yamada, Y. Fujimoto, O. Ishii, and M. Yamazaki, Electron. Lett. 46, 1285 (2010).

10. Y. Fujimoto, J. Nakanishi, T. Yamada, O. Ishii, and M. Yamazaki, Prog. Quantum Electron. 37, 185 (2013).

11. J. Nakanishi, Y. Horiuchi, T. Yamada, O. Ishii, M. Yamazaki, M. Yoshida, and Y. Fujimoto, Opt. Lett. 36, 1836 (2011).

12. M. R. Brown, J. S. S. Whiting, and W. A. Shand, J. Chem. Phys. 43, 1 (1965).

13. S. Kajikawa, T. Terao, M. Yoshida, S. Motokoshi, O. Ishii, M. Yamazaki, and Y. Fujimoto, Electron. Lett. 52, 861 (2016).

14. Y. Fujimoto, M. Nakahara, P. Binun, S. Motokoshi, O. Ishii, M. Watanabe, M. Yamazaki, T. Shinozaki, T. Sato, and Y. Yanomori, in 2019 Conference on Lasers and Electro-Optics Europe and European Quantum Electronics Conference (Optical Society of America, 2019), P. CJ_P_34.

15. M.-P. Lord, F. Maes, V. Fortin, M. Bernier and R. Vallée, in Advanced SolidState Lasers 2020, OSA Technical Digest (Optical Society of America, 2020), P. ATh5A.6.

16. M. Olivier, J.-L. Doualan, V. Nazabal, P. Camy, and J.-L. Adam, J. Opt. Soc. Am. B 30, 2032 (2013).

17. L. Del Longo, M. Ferrari, E. Zanghellini, M. Bettinelli, J. A. Capobianco, M. Montagna, and F. Rossi, J. Non-Cryst. Sol. 231, 178 (1998).

18. J. I. Adam and W. A. Sibley, J. Non-Cryst. Sol. 76, 267 (1985).

19. I. Kelson and A. A. Hardy, IEEE J. Quantum Electron. 34, 1570 (1998).

20. J. Shi, M. Tang, S. Fu, P. Shum, and D. Liu, J. Lightwave Technol. 32, 27 (2013).

21. W. Wang, L. Li, D. Chen, and Q. Zhang, Sci. Rep. 6, 31761 (2016). 


\section{Full references}

1. C. Kränkel, D. T. Marzahl, F. Moglia, G. Huber, and P. W. Metz, "Out of the blue: semiconductor laser pumped visible rare-earth doped lasers," Laser Photon. Rev. 10(4), 548-568 (2016).

2. H. Okamoto, K. Kasuga, I. Hara, and Y. Kubota, "Visible-NIR tunable $\mathrm{Pr}^{3+}$ doped fiber laser pumped by a GaN laser diode," Opt. Express 17(22), 20227-20232 (2009).

3. P. W. Metz, S. Müller, F. Reichert, D.-T. Marzahl, F. Moglia, C. Kränkel, and G. Huber, "Wide wavelength tunability and green laser operation of diode-pumped $\mathrm{Pr}^{3+}: \mathrm{KY}_{3} \mathrm{~F}_{10}$," Opt. Express 21(25), 31274-31281 (2013).

4. P. Camy, J. L. Doualan, R. Moncorgé, J. Bengoechea, and U. Weichmann, "Diode-pumped $\mathrm{Pr}^{3+}: \mathrm{KY}_{3} \mathrm{~F}_{10}$ red laser," Opt. Lett. 32(11), 1462-1464 (2007).

5. P. W. Metz, F. Reichert, F. Moglia, S. Müller, D.-T. Marzahl, C. Kränkel, and G. Huber, "High-power red, orange, and green $\mathrm{Pr}^{3+}: \mathrm{LiYF}_{4}$ lasers," Opt. Lett. 39(11), 3193-3196 (2014).

6. F. Cornacchia, A. Di Lieto, M. Tonelli, A. Richter, E. Heumann, and G. Huber, "Efficient visible laser emission of GaN laser diode pumped Pr-doped fluoride scheelite crystals," Opt. Express 16(20), 15932-15941 (2008).

7. D. Pabœuf, O. Mhibik, F. Bretenaker, P. Goldner, D. Parisi, and M. Tonelli, "Diode-pumped $\mathrm{Pr}: \mathrm{BaY}_{2} \mathrm{~F}_{8}$ continuous-wave orange laser," Opt. Lett. 36(2), 280-282 (2011).

8. R.G. Smart, J.N. Carter, A.C. Tropper, D.C. Hanna, S.T. Davey, S.F. Carter, and D. Szebesta, "CW room-temperature operation of praseodymiumdoped fluorozirconate glass-fiber lasers in the blue-green, green and red spectral regions," Opt. Commun. 86(3-4), 333-340 (1991).

9. J. Nakanishi, T. Yamada, Y. Fujimoto, O. Ishii, and M. Yamazaki, “Highpower red laser oscillation of $311.4 \mathrm{~mW}$ in $\mathrm{Pr}^{3+}$-doped waterproof fluoroaluminate glass fibre excited by GaN laser diode," Electron. Lett. 46(18), 1285-1286 (2010).

10. Y. Fujimoto, J. Nakanishi, T. Yamada, O. Ishii, and M. Yamazaki, "Visible fiber lasers excited by GaN laser diodes," Prog. Quantum Electron. 37(4), 185-214 (2013).

11. J. Nakanishi, Y. Horiuchi, T. Yamada, O. Ishii, M. Yamazaki, M. Yoshida, and Y. Fujimoto, "High-power direct green laser oscillation of $598 \mathrm{~mW}$ in $\mathrm{Pr}^{3+}$-doped waterproof fluoroaluminate glass fiber excited by twopolarization-combined GaN laser diodes," Opt. Lett. 36(10), 1836-1838 (2011).

12. M. R. Brown, J. S. S. Whiting, and W. A. Shand, "Ion-ion interactions in rare-earth-doped LaF 3 ," J. Chem. Phys. 43(1), 1-9 (1965).

13. S. Kajikawa, T. Terao, M. Yoshida, S. Motokoshi, O. Ishii, M. Yamazaki, and Y. Fujimoto, "Single-mode visible laser oscillation in Pr-doped double-clad structured waterproof fluoro-aluminate glass fibre," Electron. Lett. 52(10), 861-863 (2016).

14. Y. Fujimoto, M. Nakahara, P. Binun, S. Motokoshi, O. Ishii, M. Watanabe, M. Yamazaki, T. Shinozaki, T. Sato, and Y. Yanomori, "2 W single-mode visible laser oscillation in Pr-doped double-clad structured waterproof fluoro-aluminate glass fiber," in 2019 Conference on Lasers and ElectroOptics Europe and European Quantum Electronics Conference, OSA Technical Digest (Optical Society of America, 2019), P. CJ_P_34.

15. M.-P. Lord, F. Maes, V. Fortin, M. Bernier and R. Vallée, "Watt-level visible laser emission in a double-clad praseodymium-doped fluoride fiber," in Advanced Solid-State Lasers 2020, OSA Technical Digest (Optical Society of America, 2020), P. ATh5A.6.

16. M. Olivier, J.-L. Doualan, V. Nazabal, P. Camy, and J.-L. Adam, "Spectroscopic study and Judd-Ofelt analysis of $\mathrm{Pr}^{3+}$-doped Zr-Ba-La-Al glasses in visible spectral range," J. Opt. Soc. Am. B 30(8), 2032-2042 (2013).

17. L. Del Longo, M. Ferrari, E. Zanghellini, M. Bettinelli, J. A. Capobianco, M. Montagna, and F. Rossi, "Optical spectroscopy of zinc borate glass activated by $\mathrm{Pr}^{3+}$ ions," J. Non-Cryst. Sol. 231(1-2), 178-188 (1998).

18. J. I. Adam and W. A. Sibley, "Optical transitions of $\mathrm{Pr}^{3+}$ ions in fluorozirconate glass," J. Non-Cryst. Sol. 76(2-3), 267-279 (1985).
19. I. Kelson and A. A. Hardy, "Strongly pumped fiber lasers," IEEE J. Quantum Electron. 34(9), 1570-1577 (1998).

20. J. Shi, M. Tang, S. Fu, P. Shum, and D. Liu, "Modeling and analysis of fiber Bragg grating based visible $\mathrm{Pr}^{3+}$-doped fiber lasers," J. Lightwave Technol. 32(1), 27-34 (2013).

21. W. Wang, L. Li, D. Chen, and Q. Zhang, "Numerical analysis of $2.7 \mu \mathrm{m}$ lasing in $\mathrm{Er}^{3+}$-doped tellurite fiber lasers," Sci. Rep. 6, 31761-1-10 (2016). 